\title{
Parameters of Transportation of Tailings of Metals Lixiviating
}

\author{
Vladimir Golik ${ }^{1,2, *}$, and Yury Dmitrak ${ }^{1}$ \\ ${ }^{1}$ North-Caucasian State University of Technology, 44 Nikolaev street, Vladikavkaz, 362021, Russia ${ }^{1}$ \\ ${ }^{2}$ Vladikavkaz Scientific Center of the Russian Academy of Sciences and the Government Republic of \\ North Ossetia-Alania, 22, Markusa street, Vladikavkaz, 362027, Russia
}

\begin{abstract}
The article shows that the change in the situation in the metals market with a steady increase in production volumes is intensified against the tendency of the transition of mining production from underground mining to underground mining for a certain group of ores. The possibility of a non-waste metals extraction from not only standard, but also from substandard raw materials, is currently provided only by technology with the lixiviating of metals from developing ores. The regular dependences of the magnitude of hydraulic resistances on the hydro-mixture velocity and its density are determined. The correct values of the experimental data convergence with the calculated values of these parameters are obtained. It is shown that the optimization of the transportation parameters of lixiviating tailings allows reducing the level of chemically dangerous pollution of the environment by leachate products. The direction of obtaining the ecological and technological effect from the use of simultaneously environmental and resource-saving technology for the extraction of the disclosed metals is indicated.
\end{abstract}

\section{Introduction}

The development of the human society is accompanied by a steady increase in metals producing to meet the need for consumption. For example, over 100 years the consumption of non-ferrous and alloying metals has increased fivefold.

With the development of technological capabilities and the improvement of mining technology, low-grade and complex ores that require pre-concentration are increasingly involved in production. The lag in the possibilities of ore processors from the opportunities of its miners is evidenced by the increase in tailings processing on the surface and the volumes of substandard ore reserves lost in subsoil.

It is generally recognized that the complete elimination of the tailings of heavy metal ores processing is a radical measure of reducing the global risk for the environment of the Earth's biosphere by the toxic components.

\footnotetext{
*Corresponding author: v.i.golik@mail.ru
} 
The environmental concept for the extraction of metallic raw materials is based on the fact that, since there is no way to prevent damage to flora and fauna, tailings should be disposed properly.

The condition of the metal raw materials base allows us to summarize that Russia's supply of non-ferrous metals is insufficient, and the most of the non-ferrous metals are mined casually, and a significant number of metal ores are exported in the form of raw materials [1-2].

The possibility of wasteless extraction of metals from not only the standard, but also from the substandard raw materials, is currently provided only by the first-step technology with the lixiviating of metals (Fig. 1).

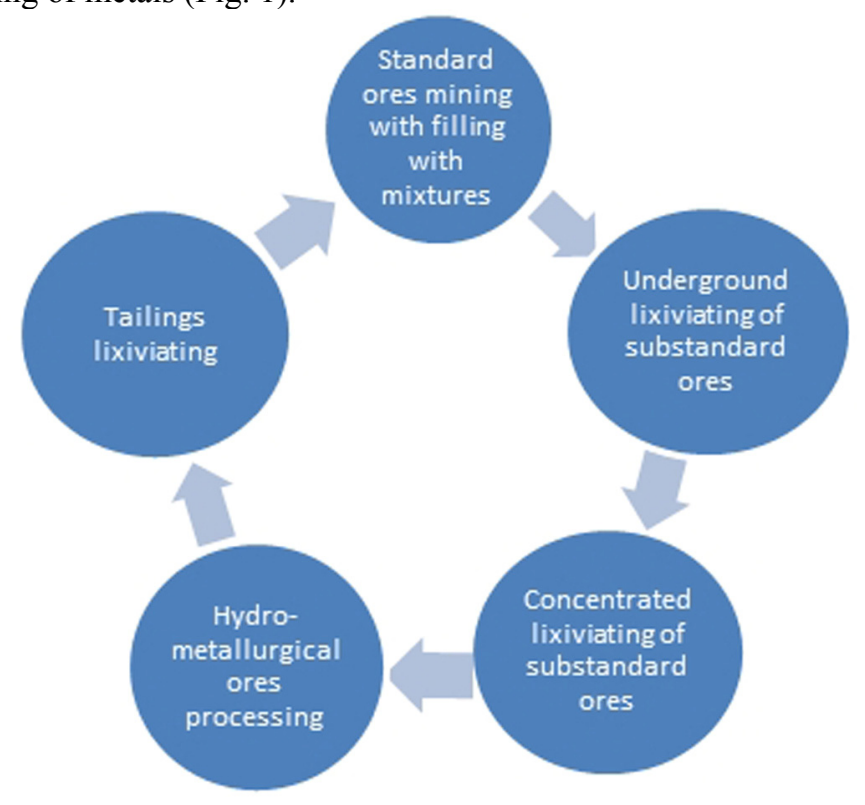

Fig. 1. Options for lixiviating metal from ores.

The concept of obtaining metals by lixiviating includes elements of a single technological cycle, including:

- extraction of relatively standard ores from the subsoil for traditional processing and creation of a compensation space for the removal of other stocks;

- extraction of metals by concentrated lixiviating from mined ores non-conditional for plant processing;

- extraction of metals from current and pre-accumulated tailings of processing and metallurgy with activation of processes by non-traditional methods [3].

Lixiviating produces a significant part of metals, for example, gold, uranium, copper. A large enterprise Priargunsky RPC (Transbaikalia) extracts most of the uranium with different lixiviating options.

The prospect of an increase in metals production by advanced lixiviating technologies forms a new problem handling with the tailings of technological lixiviating.

Technology of delivery and placement of processing tailings includes the hydraulic transport of mineral media at a ratio of solid to liquid $(\mathrm{S}: \mathrm{L})$ as $1: 6$, which is primarily done to improve the transportability of the mixture. The wastewater excess is dangerous to the hydrosphere. In mining practice, the density of transported liquid tailings is less than $1.25 \mathrm{t} / \mathrm{m} 3$ [4-5].

The mode of operation of the hydro transport system, primarily the flow velocity and the pressure depend on the density of liquid lixiviatings. Empirical methods for determining 
delivery parameters are imperfect in nature and when solving design problems, they need experimental verification in specific conditions. To achieve the objectives of this study, similar work can be used to optimize the pipeline transport of solidifying filling mixtures [6].

The purpose of research in this area of technology is to increase the reliability of hydrotransportation of condensed pulp to the storage location. The objectives of the study include: studying the composition and properties of lixiviating tailings, determining hydraulic losses and the critical speed of the hydro-mixture and developing recommendations for calculating hydro-transport parameters.

\section{Materials and methods}

Experimental studies of tailings hydro-transport of lixiviating of gold-bearing raw materials were carried out on a hydro-transport unit including pipelines, a pump, a repulpator, instruments and meters. The researched processes were modeled in a $5.5 \mathrm{~m}$ pipeline.

The critical velocity was determined from the flow rate of the hydro-mixture at the time of formation in the pipeline of a fixed layer about $1 \mathrm{~mm}$ thick. Three variants of the ratio of the solid component to the liquid component were studied: $1: 1.0 ; 1: 1.5$ and $1: 2$.

To determine the base, the values of the parameters of hydro-transport of clean water have been determined. To compare the parameters of hydro-transport of tailings with the process of thickening for $\mathrm{S}: \mathrm{L}=1: 6$, the possible variants of the ratio of solid to liquid are investigated.

The investigated material is represented by fine sandy $(0.1-0.06 \mathrm{~mm})$ and coarse dusty $(0.06-0.01 \mathrm{~mm})$ fractions with a plasticity number in the range of $1-7 \%$.

The obtained data were used in mathematical modeling of processes using alternative calculations to develop recommendations in considered case.

\section{Results and discussion}

\subsection{Loss of fall when moving the hydro-mixture}

In the course of the studies, the values of fall losses during the motion of hydro-mixtures with different pulp density $\gamma \mathrm{n}=1.11,1.13,1.19,1.22,1.26,1.32,1: 40$ were obtained.

The method of least squares the dependencies were found (Table 1):

$$
100 J_{r}=a_{1} V^{2}+a_{2} V
$$

where: $a_{1}, a_{2}-$ the empirical coefficients;

$V$ - average velocity of the flood, $\mathrm{m} / \mathrm{sec}$.

Table 1. Dynamics of hydraulic resistance.

\begin{tabular}{|c|c|c|}
\hline Sample & Density, $\mathbf{t} / \mathbf{m 3}$ & Hydraulic resistance \\
\hline 1 & 1.0 & $100 \mathrm{I}=4.334 \mathrm{~V}^{2}+2.158 \mathrm{~V}$ \\
\hline 2 & 1.11 & $100 \mathrm{I}=4.819 \mathrm{~V}^{2}+2.323 \mathrm{~V}$ \\
\hline 3 & 1.13 & $100 \mathrm{I}=4.923 \mathrm{~V}^{2}+2.347 \mathrm{~V}$ \\
\hline 4 & 1.19 & $100 \mathrm{I}=5.199 \mathrm{~V}^{2}+2.385 \mathrm{~V}$ \\
\hline 5 & 1.22 & $100 \mathrm{I}=5.308 \mathrm{~V}^{2}+2.523$ \\
\hline 6 & 1.26 & $100 \mathrm{I}=5.577 \mathrm{~V}^{2}+2.384 \mathrm{~V}$ \\
\hline 7 & 1.32 & $100 \mathrm{I}=5.726+2.747 \mathrm{~V}$ \\
\hline 8 & 1.40 & $100 \mathrm{I}=6.029 \mathrm{~V}^{2}+3.007 \mathrm{~V}$ \\
\hline
\end{tabular}


The experimental data were compared with the calculated values of the required parameters:

$$
J_{r}=J_{b} \frac{\gamma_{r}}{\gamma_{b}}
$$

where: $J_{b}$ - specific fall loss when moving clean water; $\gamma_{r}$ - density of hydro-mixture; $\gamma_{b}$ - density of water.

$$
J_{r}=J_{b}\left(1+C_{o}\right)
$$

The relative density of a solid with Archimedean force $(a)$ can be found as:

where: $\gamma_{s}-$ the density of solid particles, $\mathrm{t} / \mathrm{m}^{3}$

$$
a=\frac{\gamma_{s}-\gamma_{b}}{\gamma_{b}}
$$

The value of hydraulic losses in the transport of clean water by the Darcy method:

$$
J_{b=\frac{\lambda V}{D^{2} g}}
$$

where: $\lambda$-coefficient of hydraulic friction.

The choice of the calculated dependences for $\lambda$ depends on the ratio of the Reynolds $R_{e}$ and the limiting values of $R_{e}{ }^{l} R_{e}{ }^{2}$ :

$$
R_{e}=\frac{V D}{v}
$$

where: $v$-coefficient of kinematic viscosity, equal to: $1 \times 10^{-6}$.

$R_{e}$ values are in the limits of 75000-150000. The limited values $R_{e}$ are:

$$
R_{e}^{*}=\frac{10}{\Delta} u R_{e}^{* *}=\frac{500}{\bar{\Delta}}
$$

where: $\bar{\Delta}$ - relative roughness $(\Delta / D) ; \Delta$ - absolute roughness, $(0.4)$.

Found values of $R_{e}{ }^{*}$ and $R_{e}{ }^{* *}$ appeared to be equal to 1250 and 62500 respectively.

For $\lambda$ calculation the following formula was accepted:

$$
\lambda=\frac{8 g}{C^{2}}
$$

where: $C$ - Chezy's velocity factor.

For the area of quadratic resistance:

$$
C=\frac{R^{\frac{1}{6}}}{n}
$$

where: $R$ - hydraulic radius; $n$ - the roughness coefficient of steel pipes (0.0125).

The experimentally determined loss values have a sufficiently high convergence with the calculated values, while the specific loss at a velocity of less than $1.6 \mathrm{~m} / \mathrm{sec}$ turned out to be higher than the calculated values.

\subsection{Critical flow rate of the hydro-mixture}

The velocities of movement along the pipeline were determined from the measured flow rate of the hydro-mixture at the time of fixed silt layer formation in the pipeline.

The convergence of the values of obtained critical velocities with the calculated values is given in Table 2 . 
Table 2. Dynamics of hydraulic losses during water transportation.

\begin{tabular}{|c|c|c|c|c|c|}
\hline $\begin{array}{c}\text { Velocity, } \\
\mathbf{m} / \mathbf{s e c}\end{array}$ & $\begin{array}{c}\text { Chezy's } \\
\text { velocity } \\
\text { factor, }\end{array}$ & $\begin{array}{c}\text { Coefficient of } \\
\text { hydraulic } \\
\text { friction }\end{array}$ & $\begin{array}{c}\text { Loss of } \\
\text { pressure } \\
\text { calculated }\end{array}$ & $\begin{array}{c}\text { Pressure loss } \\
\text { experienced }\end{array}$ & Error, \% \\
\hline 1 & 38.5 & 0.05 & 5.8 & 6.6 & -11.7 \\
\hline 1.5 & - & - & 12.1 & 13.0 & -6.8 \\
\hline 2.0 & - & - & 21.5 & 21.7 & -0.6 \\
\hline 2.5 & - & - & 33.6 & 33.5 & +0.5 \\
\hline
\end{tabular}

The experimentally established dependences of pressure losses on the flow velocity are interpreted in Fig. 2.

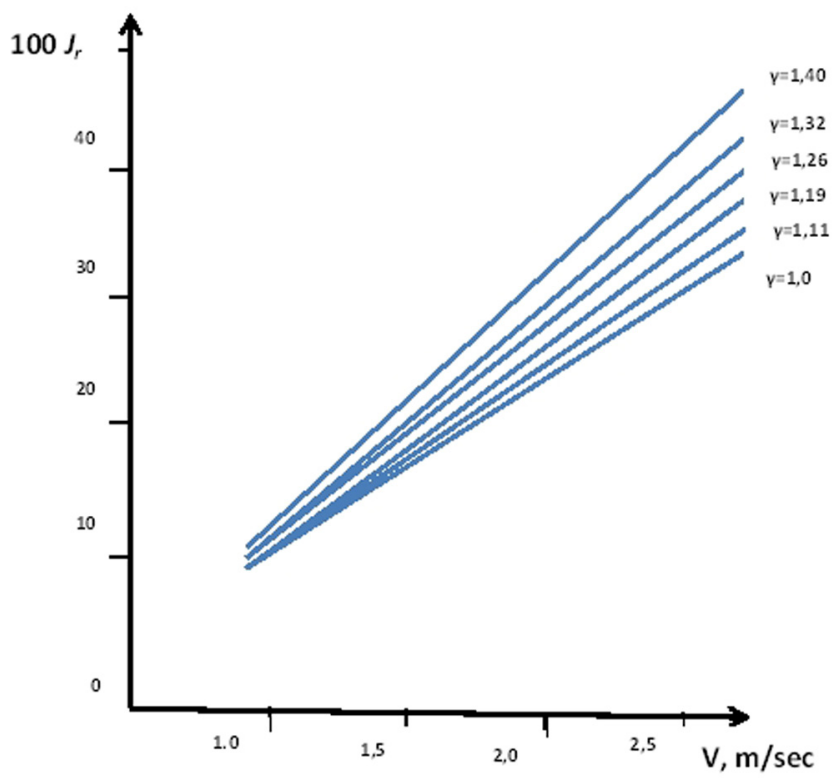

Fig. 2. The graph of the dependence of fall losses on the flow velocity.

The analysis of the results shows that the values of the critical velocities differ from the experimental values by $0-34 \%$. The best convergence of the experimental values of the critical velocities with the calculated values was established using the A.P. Yufin formula.

The established dependencies may be in demand when designing enterprises using options for lixiviating metals from developing ore.

Transportation of tails of non-ferrous metals ores hydrometallurgical processing in the optimum mode of operation of the pipeline expands the field of application of resourcesaving technologies for ore deposits development with lixiviating [7-9].

Technology with industrial controlled lixiviating reduces the danger of natural uncontrolled lixiviating, which is carried out spontaneously at mining facilities.

\section{Conclusions}

1. The danger of chemical contamination of the natural environment by the liquid tailings of lixiviating is reduced by their thickening with increasing density.

2. Optimum parameters of transportation of condensed hydro-mixtures are provided when calculating by the proposed method. 
3. Determined dependencies allow optimizing parameters of transportation of lixiviating tailings and to reduce the volume of chemically hazardous lixiviating products with the formation of ecological and technological effect.

\section{Acknowledgement}

The article contains the results of researches made under Programme Erasmus + 574061EPP-1-2016-1-DE-EPPKA2-CBHE-JP "Modernization of geological education in Russian and Vietnamese universities".

\section{References}

1. V.I. Golik, Int. Bus. Man. 9:6, 1209-1216 (2015)

2. G. Wang, R. Li, E.J.M. Carranza, F. Yang, Ore Geol. Rev. 71, 592-610 (2015)

3. Weijing Wang, Shaofeng Huang, Xiaobo Wu, Qingfei Ma, J. Soft. Eng. App. 4, 329334 (2011)

4. Xiao Li-Ping, Study on Pollution Laws of Coal Gangue Leaching Solution to Groundwater System (Fuxin: Liaoning Technical University, 2007)

5. I. Onica, E. Cozma, T. Goldan, AGIR Rev. 3, 14-27 (2006)

6. Zhen-Dong Liu, Gan-Jiang Tao, Qing-Yun Ren, Dong-Sheng Yang, J. Chi. Coal Soc. 35:4, 450-455 (2011)

7. Haifeng Wang, Yaqun He, Chenlong Duan, Yuemin Zhao, Youjun Tao, Cuiling Ye, Development of Mineral Processing Engineering Education in China University of Mining and Technology (Springer-Verlag, Berlin, 2012)

8. T. Chen, C. Lei, B. Yan, X. Xiao, Hydrometallurgy, 147, 178-182 (2014)

9. C. Zhou, Z. Gong, J. Hu, A. Cao, H. Liang, Waste Manag. 35, 191-198 (2015) 